\title{
O poder militar do Sol Nascente: o Japão, a militarização e o entorno regional
}

\author{
The military power of the Rising Sun: \\ Japan, the militarization and regional power
}

Rev. Bra. Est. Def. v. 4, nº 1, jan./jun. 2017, p. 203-228

DOI: $10.26792 /$ RBED.v4n 1.2017.71859

\section{ALANA CAMOÇA GONÇALVES DE OLIVEIRA}

\section{INTRODUÇÃO}

No século XXI o equilíbrio de poder no Leste Asiático, sobretudo no Nordeste Asiático, passou por significativas transformações e, em um cenário de constantes mudanças na arquitetura do sistema internacional, a região tem conquistado grande importância tanto do ponto de vista econômico como geopolítico. Nesse sentido, por exemplo, as tensões no Mar do Sul $^{1}$ e no Mar do Leste da China ${ }^{2}$ que têm reacendido a relevância de se estudar a história das relações diplomáticas entre os atores regionais e as disputas territoriais da região asiática. Além disso, o projeto da Nova Rota da Seda (One Belt, One Road), que vem se consolidando com investimentos bilionários por parte do governo chinês, o fim do TPP (Transpacific Partnership) e, principalmente, o lançamento de mísseis da Coreia do Norte, tem estimulados alguns estudos sobre a região, devido a complexidade de alianças, rivalidades e de poder.

Um dos atores elementares para a compreensão de toda a lógica de poder na balança asiática é o Japão, visto que, ao final da Segunda Guerra Mundial (1939-1945), os EUA iniciaram a ocupação do território japonês com o objetivo de desmilitarizar e democratizar o país com o intuito de afastar qualquer ameaça soviética e também como uma forma de manter um pólo de influência no Leste da Ásia. Sob proteção norte-americana, o Japão se desenvolveu economicamente, enquanto se manteve sob égide de tratados e acordos de segurança com os EUA. O final da Segunda Guerra Mundial não só marcou profundamente o comportamento japonês, como

Alana Camoça Gonçalves de Oliveira - Doutoranda em Economia Política Internacional pelo Programa de Pós Graduação em Economia Política Internacional da Universidade Federal do Rio de Janeiro (UFRJ). 
transformou sua estrutura política, econômica e militar. Assim como possibilitou a capilaridade do poder de influência e de ação dos EUA, seja durante a Guerra Fria ou na atualidade.

Nesse sentido, o artigo pretende compreender o Japão com ênfase à insegurança e a sua política externa no Pós-Segunda Guerra Mundial, através de uma análise voltada para: a) as relações próximas do Japão com os EUA; b) a constituição das Forças de Autodefesa; e c) o cenário instável de segurança no entorno regional. A hipótese central do artigo é de que o entorno regional conflituoso servem como justificativa do ponto de vista interno e externo para a busca pela "remilitarização". Argumenta-se que a despeito da existência de Forças de Autodefesa, não se pode considerar que o Japão é desmilitarizado ou inofensivo no cenário asiático.

$\mathrm{O}$ artigo foi separado em três partes: no primeiro momento trazemos o debate sobre segurança internacional; na segunda parte é feito um debate sobre o Japão no Pós-Segunda Guerra Mundial, onde analisamos as Forças de Autodefesa (FAD); e por fim, na terceira parte, apresentamos um debate sobre os gastos militares e a insegurança na região do Leste asiático.

\section{O DEBATE SOBRE A SEGURANÇA INTERNACIONAL: A INSERÇÃO JAPONESA}

A Segurança Internacional é um dos principais campos de pesquisa na área das relações internacionais, visto que está no topo das preocupações, das discussões e das agendas, sejam elas nacionais, regionais ou mundiais. A preservação da vida, a sacralidade e importância da vida humana, a guerra, a paz, o comportamento animalesco dos homens em situações adversas, as dissuasões como consequência da própria arquitetura do sistema internacional e a busca por poder são algumas das questões que são elencadas ao estudarmos sobre segurança.

É com a ambição de estudar a guerra e os motivos que levaram aos grandes conflitos no século XX que surgem os Estudos de Segurança, que tem como bases teóricas os estudos de geopolítica e estratégia. Nesse sentido, as conceituações tradicionais do pensamento de segurança no campo das relações internacionais começam a partir da preocupação de alguns autores, sobretudo, para aqueles que compreendem o sistema internacional como anárquico - um ambiente onde insegurança impera sem impeditivos ou mecanismos capazes de frear as ambições e os desejos expansivos dos Estados (Morgenthau 2003).

De acordo com John Herz (1950), em uma sociedade anárquica há um jogo de soma-zero, no qual o poder adquirido por um estado implica no declínio da segurança de outro. Na busca por autoproteção, os Estados ad- 
quirem mais poder no intuito de afastar o possível impacto de domínio dos outros países, em consequência, os outros ficam mais inseguros e também acumulam poder. Nesse sentido, a segurança implica na capacidade de uma nação defender-se ou derrotar um determinado país ou uma determinada ameaça.

Barry Buzan escreveu em 1983 o livro People, States and Fear: The National Security Problem in International Relations, criando um marco e um legado para os estudos de segurança internacional e, desde então, tratar sobre segurança internacional no ocidente implica estudar a obra do autor. Em 1991 é publicada a segunda edição da obra de Buzan, intitulada People, States and Fear: an Agenda for International Security Studies in the Post-Cold War Era, e neste livro o autor aborda uma perspectiva cada vez menos estadocêntrica, apesar de ainda compreender o Estado como uma das peças chave nas questões sobre segurança internacional (Buzan 1991a; Tanno 2003).

De acordo com Buzan e Hansen (2012, 37), "a segurança diz respeito a constituir algo que precisa ser assegurado: a Nação, o Estado, o indivíduo, o grupo étnico, o meio ambiente ou o próprio planeta”. Argumenta-se que assim como o que ocorre no interior de um Estado está susceptível a afetar a segurança internacional ou regional, o panorama externo afeta diretamente a segurança interna de cada um dos países.

A segurança e a insegurança de determinados Estados no sistema internacional variam de acordo com as ameaças e o próprio papel do país nas tomadas de decisão internacionais. O Canadá se sente muito mais seguro com relação às ameaças devido às suas relações estáveis e amigáveis com grande parte dos países do globo, enquanto o Japão, no Leste Asiático, se sente ameaçado diante das incursões e testes nucleares da Coreia do Norte nas proximidades territoriais marítimas. Portanto, a insegurança e a segurança no sistema internacional variam das diferentes realidades e contextos regionais (Wolfers 1952; Buzan 1991b).

O Japão é composto por quatro ilhas principais: Hokkaido, Honshu, Shikoku e Kyushu; e mais de seis mil ilhas pequenas espalhadas nas proximidades do Pacífico, precisamente no Mar do Leste. Como o Japão é um arquipélago, possui uma dependência da pesca e de atividades voltadas para o mar e, por esse motivo, de territórios marítimos e rotas para suprir às suas necessidades internas, visto que além de ser uma região localizada no Círculo de Fogo do Pacífico, seu território é repleto de áreas montanhosas. Devido às questões geográficas da própria constituição do arquipélago, o Japão precisa importar grande quantidade de commodities e, principalmente, recursos energéticos. ${ }^{3}$

É possível notar que a posição de um determinado país no cenário internacional o coloca diante de constrangimentos específicos, o que in- 
fluencia diretamente o comportamento e suas tomadas de decisão, tanto no âmbito interno como externo, além de estimular relações amigáveis ou rivalidades.

Pelo fato das características geográficas dos Estados serem relativamente imutáveis e inalteráveis, as demandas geográficas dos Estados permanecerão as mesmas por séculos, e pelo fato de que o mundo ainda não alcançou aquele feliz momento onde os desejos de um homem não conflitam com os desejos de outro homem, estas demandas irão causar atrito. Por isso, podemos colocar na geografia a culpa por muitas lutas duradouras que aparecem persistentemente através da história, enquanto governos e dinastias se erguem e sucumbem (Spykman 1938, 9, tradução nossa). ${ }^{4}$

No âmbito da estratégia, o Japão só tem saída livre sem empecilhos pelo Leste e é cercado por países com os quais tem relações econômicas estáveis, mas dissuasões políticas históricas. A presença da China, da Coreia do Norte e da Rússia em sua proximidade, países com os quais o Japão já travou guerras como no caso da Primeira Guerra Sino-Japonesa (1894-1895), a Guerra Russo Japonesa (1904-1905), Ocupação Japonesa da Coreia (1910-1945) e a Segunda Guerra Sino-Japonesa (1937-1945), é uma questão fulcral para pensarmos o equilíbrio de poder na região e a insegurança apresentada nos livros de Defesa do Japão.

Do ponto de vista do neorrealismo ofensivo de Mearsheimer (2001), os EUA seriam o único hegemon ${ }^{5}$ regional na história contemporânea, visto que apesar de outros Estados terem lutado guerras com o objetivo de conquistarem a hegemonia regional, como foi o caso do Japão imperial, da França napoleônica e da Alemanha nazista, nenhum conseguiu de fato tal proeza. No caso asiático, um cenário de grandes potências impossibilitaria a elevação de um dos países ao status de hegemon regional. Além disso, nas palavras de Mearsheimer $(2001,88)$ a presença dos EUA como aliado estratégico do Japão exerce pressão no território, servindo como mediador e como aliado de alguns países em disputas territoriais, como é o caso da disputa pelas ilhas Senkaku/Diaoyu/Diaoyutai entre Japão, China e Taiwan (Mearsheimer 2001, 2004).

\section{O JAPÃO E O EUA: AS FAD, A CONSTITUIÇÃO DE 1947 E A RECONSTRUÇÃO}

Depois de refletir profundamente as tendências gerais do mundo e as condições atuais que temos hoje em Nosso Império, decidimos aceitar uma solução para a situação atual recorrendo a uma medida extraordinária. Pedimos ao nosso Governo que comunique 
aos Governos dos Estados Unidos, da Grã-Bretanha, da China e da União Soviética que o nosso Império aceita as disposições previstas em sua Declaração Conjunta.[…] Nós declaramos guerra à América e à Grã-Bretanha com o nosso sincero desejo de garantir a autopreservação do Japão e a estabilização do Leste Asiático [ .... a situação da Guerra não se desenvolveu necessariamente em favor do Japão, ao mesmo tempo em que as tendências gerais do mundo se voltaram contra os nossos interesses. O inimigo, além disso, começou a empregar uma nova e mais cruel bomba, seu poder de fazer danos é, de fato, incalculável, capaz de tirar a vida de muitos inocentes. Se continuássemos a lutar, isso resultaria não somente no colapso total e obliteração da Nação japonesa, mas também nos levaria em direção à total extinção da civilização humana ${ }^{6}$ (Hirohito speech 1945, tradução nossa).

Após a Segunda Guerra Mundial, o Japão passou por um período de ocupação das Forças Aliadas sob o comando dos EUA, que durou de 1945 até 1952. A Força de Ocupação foi liderada pelo general Douglas MacArthur, que tinha como principais objetivos promover reformas políticas e econômicas no país. Esse período é marcado pelos três D’s: i) democratização; ii) desmilitarização; e iii) desmonopolização (Gordon 2003; Uehara 2003).

Neste período foi redigida a Constituição de 1947, que é um marco histórico na política japonesa, visto que promoveu duas importantes mudanças. A primeira delas é que o sistema político japonês foi modificado e, apesar de permitir a continuidade do sistema imperial, o Imperador passou a representar apenas um símbolo do país, sem qualquer participação política. Em decorrência disso, um sistema político misto foi arquitetado, onde o parlamento é quem governa e tem poder de decisão no Japão, adotando uma legislatura bicameral ${ }^{7}$ (Watanabe 2011, 10).

A segunda mudança e mais importante para este artigo foi a restrição imposta pelo artigo $9^{\circ} .{ }^{8} \mathrm{O}$ direito do Japão de fazer guerra não é mais reconhecido pelo Japão e houve a proibição do Japão constituir Forças Armadas sejam marítimas, terrestres ou aéreas.

Artigo 9. Aspirando sinceramente a paz mundial baseada na justiça e ordem, o povo japonês renuncia para sempre o uso da guerra como direito soberano da Nação ou a ameaça e uso da força como meio de se resolver disputas internacionais. Com a finalidade de cumprir o objetivo do parágrafo anterior, as forças do exército, marinha e aeronáutica, como qualquer outra força potencial de guerra, jamais serão mantidas. O direito a beligerância do Estado não será reconhecido.9 (Constitution of Japan 1947, tradução nossa). 
O texto constitucional serviu como alicerce para a nova estrutura do governo japonês, criando um regime sem direito a guerra e sem a possibilidade de investimentos massivos em produtos bélicos. A partir desse momento o Japão renunciou a força militar permanente e detém apenas uma força de autodefesa, mantendo-se sob proteção dos EUA (Christensen 1999; Foorsberg 2000; Gordon 2003). O fortalecimento das relações bilaterais Japão-EUA foi uma consequência, com a assinatura de dois tratados em 1951: o Acordo de Paz de São Francisco ${ }^{10}$ e o Acordo de Segurança Mútua Japão-EUA (Pyle 2007, 234). O primeiro devolvia a soberania japonesa do seu território e o segundo permitia que os EUA instituíssem uma base em território japonês. ${ }^{11}$

Outro tratado assinado nesse período foi o Mutual Security Assistance (MSA), que foi designado para consolidar o sistema de aliança norte americano através do fornecimento de armas e equipamentos. O Japão passou a equipar-se de materiais pesados, de caças, o que foi importante para os EUA ter como apoio no contexto da Guerra Fria e da proximidade geográfica do Japão com a China (Pyle 2007).

Diante disso, obrigado a afastar-se do poder militar, houve a justificativa da concentração dos esforços japoneses aos temas econômicos. $\mathrm{O}$ Japão voltou-se aos olhares para uma política externa baseada em elementos econômicos, fugindo da política militarista. Na década de 1950, o primeiro-ministro Shigero Yoshida (1946-1947/1948-1954) estabeleceu diretrizes para a política externa japonesa que canalizavam os esforços do país para o desenvolvimento econômico (Junior 2008, 21). Historicamente, a política externa japonesa defendia, desde o final da Segunda Guerra Mundial, os princípios da Doutrina Yoshida: ${ }^{12}$ 1) recuperação econômica como primeiro objetivo nacional; 2) dependência militar dos EUA, tendo em vista o artigo $9^{\circ}$ da Constituição de 1947 ; 3) bilateralismo nas relações internacionais, tendo como prioridade a aliança com os EUA; e 4) participação nos organismos multilaterais - principalmente na Organização das Nações Unidas (ONU) -, com o intuito de melhorar a imagem externa do país no exterior (Uehara 2003; Pyle 2007; Hamada; Mimaki 2011, 140).

Os principais pontos da Doutrina Yoshida foram colocados em prática a partir de 1950, sendo eles: i) a recuperação econômica como o primeiro objetivo nacional; ii) o Japão investiria $1 \%$ do PIB no setor militar e evitaria envolvimento em assuntos político estratégicos; iii) e para garantir sua segurança a longo prazo, o país iria ceder seu território para bases às Forças Armadas aos EUA (Cooney 2006, 36). Nesse sentido, observa-se que a política externa japonesa esteve orientada para a fortificação das relações bilaterais Japão-EUA e com auxílio norte americano através da ajuda financeira e as diretrizes da Doutrina Yoshida, o Japão pode crescer 
economicamente e aos poucos se reestabelecer como potência no sistema internacional (Torres 1997).

Nesse sentido, desde o final da Ocupação em 1952, os governos japoneses evitaram assuntos relacionados a temática de defesa, porque o assunto ainda era frágil e dificilmente debatido tanto na sociedade e como nas relações com as potências estrangeiras, por esse motivo foi criado (Uehara 2003, 3). Entretanto, isso não significava dizer que tal tema não fosse debatido, pelo contrário, o militarismo e o pacifismo sempre lideraram as preocupações japonesas após a Segunda Guerra Mundial, os paradigmas se tornaram alvos de um intenso debate político sobre possíveis mudanças constitucionais.

De acordo com Hashimoto (2016), as mudanças no sistema internacional, com a ascensão das diferentes visões sobre como o Japão deve se comportar não só na região, mas no sistema internacional, fez com que o Japão tivesse que se decidir entre manter uma postura pacifista, voltar ao militarismo ou ainda buscar uma reconciliação com a Ásia. Mesmo que todos estejam motivados pelas memórias de humilhação e derrota, eles diferem suas estratégias e representam diferentes formas para reparar a espinha dorsal moral da sociedade que ainda não sabe lidar efetivamente com os traumas do Império, da guerra e da derrota (Hashimoto 2016, 2).

As visões apoiadas na ideia de militarismo concentravam-se em visões nacionalistas sobre a necessidade do Japão apagar o estigma de derrota e visavam uma transformação e mudança na posição do Japão no cenário internacional. O caminho do pacifismo era concentrado em superar a derrota se tornando uma nação respeitada moralmente no mundo, promovendo ajuda humanitária e participando de instituições que promovessem a paz (Hashimoto 2016, 4). A despeito da busca por afastar as sombras do passado:

As nações ocidentais basicamente não tem medo do Japão militarmente, mas muitas nações asiáticas tem preocupações baseadas nas experiências históricas com o militarismo japonês. Nações ocidentais prefeririam que o Japão fosse um ator mais ativo no cenário internacional, enquanto domesticamente no Japão e as nações asiáticas sentem que o Japão não está pronto para este papel. Com relação ao Japão, o mundo estaria dividido entre aqueles que acreditam que o Japão tem algo para oferecer a comunidade internacional e aqueles que não ${ }^{13}$ (Cooney 2006, 45, tradução nossa).

No que concerne o século XXI, o nacionalismo ganhou destaque com a ascensão de Shinzo Abe (2012-) ao poder, com a volta do militarismo como pensamento dominante não só nas estratégias do governo, como no pensamento da população, que temia cada vez mais os vizinhos regionais. No 
século XXI cabe destaque o segundo mandato do governo de Shinzo Abe (2012-) na retomada de propostas sobre a necessidade de revisitar o artigo $9^{\circ}$ da Constituição, com a busca pela "remilitarização" do Japão. Aquilo que é notado no Japão do século XXI é uma parcela da população aliada às ideias pacifistas e outra que apoia a "remilitarização" diante das ameaças do entorno regional asiático (Berger 2014).

Ao retornar o poder em 2012, Shinzo Abe defende os ideais de que o Japão precisa "rejuvenescer". A política externa do governo de Abe também contou com forte nacionalismo e buscou aliar-se com EUA, Índia e Austrália como forma de cercar um dos principais inimigos do momento, a China. Nesse contexto, Tóquio forneceu equipamentos militares e apoio financeiro a países como Filipinas e Vietnã e fortaleceu a imagem do país no mundo, como uma estratégia de tornar o Japão global novamente (Berger 2014).

\section{O surgimento das forças de defesa}

Apesar de muito se mencionar sobre o fato do Japão ser desprovido de forças militares ou Forças Armadas, no campo da defesa o Japão não ficou desprovido de qualquer mecanismo de segurança, pois em 1950 foi constituída a Reserva de Polícia Nacional ${ }^{14}$ (RPN) que surgiu por necessidade norte-americana de proteger o Japão de ameaças na Ásia. A Guerra da Coreia (1950-1953) teve o efeito de colocar o governo norte-americano mais engajado na questão do Pacífico e reforçou o senso de urgência de consolidar o Japão como um aliado anticomunista (Maeda 1995; Forsberg 2000, 3; Cooney 2006).

A Guerra da Coreia acelerou muitas tendências, mesmo que as diretrizes da política americana em relação ao Japão, Coreia, China e Vietnã pelos vinte anos seguintes já tivesse sido traçada antes da guerra. Talvez Yoshida Shigeru tenha dito uma verdade (se não a verdade) quando ele previu, em 1950, que assim como houve uma mudança da balança de poder entre as colônias americanas e o Império Britânico mais de um século antes, se o Japão se tornasse temporariamente uma "colônia dos EUA, eventualmente isso o faria mais forte" 15 (Schaller 1985, 298).

Nota-se que a Guerra da Coreia impulsionou a recriação de uma Indústria de Defesa no Japão, devido às demandas crescentes norte americanas e gastos militares na guerra que ultrapassavam 10\% do PIB dos EUA. Durante a guerra os Estados Unidos usaram diversas bases japonesas para reparar e dar suporte a tropas, assim como as bases serviram de armazenamento para materiais e alimentos para os soldados, providenciando navios para auxiliar 
o transporte de tropas e mantimentos para a guerra da Coreia, assim como mandaram alguns policiais para ajudar com os feridos.

Segundo Forsberg (2000), a guerra estimulou a economia japonesa, tendo em vista que o Japão comercializou serviços, automóveis, indústria têxtil, etc. (Forsberg 2000, 57). De acordo com Maeda (1995), a FAD foi uma forma do Japão aos poucos promover o rearmamento a partir da metade do século XX, e ao longo dos anos os governos buscaram aumentar as capacidades de atuação da FAD dentro do limite constitucional. No século XXI a FAD ${ }^{16}$ continua a carregar o objetivo de servir exclusivamente para fins defensivos, mesmo que o conceito de defesa tenha sido ampliado e possa ser encarado ambiguamente (Cooney 2006).

Na década de 1960 o Japão cresceu mais de 10\% ao ano e se integrou à economia global, unindo o GATT, em 1963 e o FMI e a OCDE, em 1964 (Gao 1997, 227). Todavia, com as crises do petróleo durante a década de 1970 há uma desaceleração do crescimento econômico nipônico, o que gera uma mudança na política externa japonesa, que se desdobra para além das relações bilaterais Japão-EUA. O Japão precisou diversificar suas relações com as nações de outros continentes e até mesmo na Ásia. ${ }^{17} \mathrm{O}$ crescimento econômico continuou e inclusive nos anos 1980, onde o Japão superou os EUA como líder no setor bancário, tecnológico e de manufaturas, além de ultrapassar os EUA como o maior fornecedor de Ajuda Oficial para o Desenvolvimento (ODA) e tornou-se ainda o principal fornecedor de recursos aos países em desenvolvimento (Uehara 2003, 2).

A partir da recuperação econômica do Japão, as nações ocidentais questionaram o fato do Japão não participar mais ativamente da manutenção de paz e da estabilidade no cenário internacional. O Japão tendia a separar assuntos políticos dos econômicos, com isso o Japão se apresentava no mundo como potência econômica e somente com interesses econômicos, sendo constantemente criticado. Diante disso, no Pós-Guerra Fria, o Japão precisou modificar a atuação de sua política externa no cenário internacional devido a alguns incidentes, sendo um deles a Guerra do Golfo (1990-1991). ${ }^{18}$

Antes da Guerra do Golfo, os políticos japoneses nunca pensaram na ideia de mandar Forças de Defesa para outros países. As pressões continuaram por parte dos EUA e algumas nações européias, com isso o governo japonês aprovou em 1990 o plano para mandar o "United Nations Peace Cooperation Team" para a Arábia Saudita, mas devido a protestos dentro do Japão a lei ${ }^{19}$ foi retirada e só é aceita dois anos depois. ${ }^{20}$ Ainda na década de 1990 o Japão participa de missões humanitárias com ajuda financeira e humana: Camboja, Moçambique, El Salvador, Golan Heights e Angola. ${ }^{21}$ 


\section{ASCENSÃO DO SOL NASCENTE: DESAFIOS EXTERNOS E A "REMILITARIZAÇÃO” NO SÉCULO XXI}

No entorno regional japonês interagem uma potência em contínua ascensão - a China -, uma potência econômica que visa se tornar um "Estado Normal" se remilitarizando - o Japão -, uma nação com altos gastos militares e que partilha de receios históricos profundos na relação com seus vizinhos - a Coreia do Sul -, uma nação que constantemente faz testes de força com o objetivo de demonstrar seu poder no cenário internacional e garantir a manutenção do regime - a Coreia do Norte -, uma comunidade política que busca ser considerada soberana - Taiwan e uma potência que afeta diretamente a configuração de poder global e o equilíbrio regional - os Estados Unidos (EUA) (Magalhães 2007).

Como mencionamos, o escalonamento de disputas territoriais tanto no Mar do Sul como no Mar do Leste. A China tem conflitos com diversos países como Japão, Taiwan, Brunei, Filipinas, Indonésia, Malásia, Vietnã e Coreia do Sul estimulam o debate sobre insegurança na região. Considerando os três principais atores na região do Leste Asiático China, Japão e EUA - há uma instabilidade proveniente dos próprios gastos expressivos de defesa.

\section{Entorno regional e gastos militares}

Os três grandes problemas do Japão com seu entorno regional do Leste Asiático são a Coreia do Norte e a China. Desde o início do século XXI são constantes os treinamentos e lançamentos de mísseis norte-coreanos nos mares próximos ao Japão, tanto que desde 2007 existe uma cooperação entre o Japão e os EUA para a construção de um escudo antimísseis. ${ }^{22}$ Com relação a China, as dissuasões são frequentes em termos territoriais e políticos, mas se mantém estáveis ou em ascendência quando a questão é comércio, visto que a China é o principal parceiro japonês em termos econômicos. ${ }^{23}$ As relações são conturbadas devido ao Japão ter sido o primeiro país a romper com o sistema sinocêntrico tributário ${ }^{24}$ e, principalmente, divido as duas guerras sino-japonesas. ${ }^{25} \mathrm{~A}$ guerra trouxe cicatrizes que ainda não foram curadas, posto que é constantemente relembrado pelo governo chinês a humilhação que a China vivenciou de potências estrangeiras no século XIX e XX (Meissner 2006).

Nos Livros Brancos de Defesa do Japão desde 2005 são retratadas as questões estratégicas no âmbito da segurança e constantemente tratam da relação do Japão com seus vizinhos regionais ${ }^{26}$ (Defense of Japan 2005; 2006; 2007; 2008; 2009; 2010; 201 1; 2012; 2013; 2014; 2015). Nos livros 
são constantemente tratados os treinamentos militares, capacidades e gastos de defesa. Entretanto, a partir de 2006 os países são apresentados de forma mais específica e com maior rigor a respeito das despesas e das aproximações vias aéreas ou marítimas de territórios japoneses. A respeito da China são retratadas as animosidades chinesas com vizinhos em territórios no Sudeste asiático, as ilhas Spratlys e Paracells. Com relação a China, os livros tratam a temática enfatizando questões de insegurança devido aos gastos em defesa (Tabela 1) e a expansão chinesa para os mares e territórios próximos de delimitações territoriais japonesas.

$\mathrm{Na}$ frente militar, a China tem fortalecido suas forças militares de forma ampla e rápida através dos grandes aumentos no seu orçamento de defesa. (...) Como parte de tais esforços, acredita-se que a China está aumentando suas capacidades militares assimétricas para dissuadir as forças militares de outros países de se aproximarem e avançarem para a região vizinha da China e de inibir suas atividades militares $^{27}$ (...) (Livro Branco da Defesa do Japão 2014, 32-33, tradução nossa).

Além disso, desde 2006 são retratadas ações chinesas em territórios marítimos japoneses, pontuando também sobre a exploração de campos de gás e petróleo nos campos de Chunxiao. As Ilhas Senkaku aparecem nos livros de defesa a partir de 2010 de maneira mais incisiva devido a proximidade de navios pesqueiros na região e inclusive as reivindicações de Taiwan. ${ }^{28}$

Os chineses e japoneses viveram como vizinhos asiáticos por quase dois mil anos. Estando geograficamente bem perto e ao mesmo tempo psicológicamente afastados, apesar das raízes culturais, os dois povos desenvolveram um sentimento ao mesmo tempo de semelhança e disparidade, interdependência e autonomia, respeito mútuo e suspeita, atração e repulsão, admiração e condescendência uns com os outros $^{29}$ (Pyle 2007, 316, tradução nossa).

Nos livros o Ministério de Defesa do Japão constantemente pontua que o ambiente de segurança que cerca o Japão tem se tornado cada vez mais grave, com vários desafios e fatores de desestabilização. A China, por exemplo, no ano de 2015, gastou com de $\mathrm{U} \$ 215$ bilhões, muito longe da quantia gasta pelos EUA, mas deve-se considerar que o poder chinês se concentra, sobretudo, nas suas esferas de influência na Ásia e em algumas regiões da África, ao contrário dos EUA que possuem bases no mundo todo. 
TABELA 1 - Forças Militares Chinesas ${ }^{30}$

\begin{tabular}{|l|c|}
\hline \multicolumn{1}{|c|}{ Forças Armadas } & Número \\
\hline Exército & $1,600,000$ \\
\hline Marinha & 235,000 \\
\hline Forças Aéreas & 398,000 \\
\hline Forças Estratégicas (Mísseis) & 100,000 \\
\hline Paramilitares & 660,000 \\
\hline Reserva & 510,000 \\
\hline Total & $3,503,000$ \\
\hline
\end{tabular}

Fonte: Elaboração própria com base nos dados do IISS, 2016

No caso japonês, no que diz respeitos às forças de defesa, é importante considerar que o Japão, apesar das restrições constitucionais, é um dos países que mais gasta com defesa no mundo. Somente no ano de 2015 o Japão gastou US $\$ 46$ bilhões em defesa, seja financiando suas Forças de Autodefesa, seja na aquisição de equipamentos militares, ou no auxílio de custo às forças militares norte-americanas em seu território. É de extrema importância levar em consideração que tal quantia faz com que o Japão seja o $8^{\mathrm{o}}$ país que mais gasta com defesa no mundo. ${ }^{31}$

TABELA 2 - Forças Militares Japonesas

\begin{tabular}{|l|c|}
\hline \multicolumn{1}{|c|}{ Forças De Defesa } & Número \\
\hline Forças de Defesa Terrestres & 151,000 \\
\hline Forças de Defesa Marítima & 45,500 \\
\hline Forças de Defesa Área & 47,100 \\
\hline Forças Centrais & 3,550 \\
\hline Paramilitares & 12,650 \\
\hline Reserva & 56,100 \\
\hline Total & 315,900 \\
\hline
\end{tabular}

Fonte: Elaboração própria com base nos dados da IISS, 2016

No século XXI a insegurança se tornou algo crucial para compreendermos a "remilitarização" e o discurso de defesa do Japão. No governo de Junichiro Koizumi (2001-2006) houve um estreitamento de laços entre o Japão e os EUA, onde após o 11 de setembro o governo japonês modificou a interpretação constitucional e autorizou o envio das FAD para assistir 
os EUA e seus aliados, através do envio de médicos, transporte, abastecimento e proteção. Ainda em 2001 foi aprovada a Lei de Medidas Especiais Antiterroristas e previa que as FAD poderiam ser enviadas com o intuito de fornecer apoio aos EUA e seus aliados ${ }^{32}$ (Mastanduno 2003; Watanabe 2016).

Entretanto, apesar da possibilidade do envio das FAD para o exterior em determinadas situações, somente no governo do primeiro ministro Shinzo Abe foi possível, quando a insegurança e o nacionalismo japonês ganham fôlego diante de um cenário cada vez mais turbulento. No artigo escrito por Shinzo Abe (2012) e intitulado Asia's Democratic Security Diamond, tal questão se torna evidente, pois o primeiro ministro demonstra os receios com relação a expansão da China para os mares do Sul, entendendo a projeção chinesa como uma ameaça para a paz e a estabilidade dos oceanos. ${ }^{33}$

No entanto, cada vez mais, o Mar da China Meridional parece tornar-se um "Lago Pequim", que os analistas dizem que será para a China o que o Mar de Okhotsk foi para a Rússia soviética: um mar profundo o suficiente para que a Marinha do Exército de Libertação do Povo baseie suas armas nucleares - submarinos de ataque motorizados, capazes de lançar mísseis com ogivas nucleares. Em breve, o porta-aviões do recém-construído da PLA Navy será uma visão comum - mais do que suficiente para assustar os vizinhos da China ${ }^{34}$ (Abe 2012, tradução nossa).

Afinal, apesar desse assunto ser revisitado durante o século XXI diversas vezes, o governo do século XXI conquistou mais espaço para a discussão. Dessa forma, são recorrentes discursos oficiais de governo e notícias a respeito do conflito pelas Ilhas Senkaku/Diaoyu são recorrentes devido a presença mais forte da China no território ${ }^{35}$ (Oliveira, 2015).

Um feito recente do governo Shinzo Abe foi a aprovação, em setembro de 2015, pelo parlamento japonês, tanto na Upper House como na Lower House, de uma lei permitindo os militares japoneses participassem de novo em operações militares internacionais, em situações em que a ameaça não afeta diretamente o Japão, mas alguns de seus aliados, no caso a medida foi direcionada para ajudar os EUA (Japan Times 2015).

No caso norte-americano a capilaridade do poder é evidente tanto do ponto de vista de poder latente devido a capacidade socioeconômica e a influência em instituições internacionais, assim como de poder militar como o país que mais gasta em defesa no mundo, só em 2017 o orçamento total foi de U\$583 bilhões. 
TABELA 3 - Tropas USPACOM em territórios estrangeiros

\begin{tabular}{|l|c|c|c|c|c|}
\hline & US Army & US Navy & $\begin{array}{c}\text { US Air } \\
\text { Force }\end{array}$ & $\begin{array}{c}\text { US } \\
\text { Marine } \\
\text { Corps }\end{array}$ & Total \\
\hline Japão & 2,300 & 19,600 & 12,400 & 15,700 & 50,000 \\
\hline Coreia do Sul & 19,200 & 250 & 8,800 & 250 & 28,500 \\
\hline $\begin{array}{l}\text { Outros (Austrália, Tailândia } \\
\text { e Singapura) }\end{array}$ & S/D & S/D & S/D & S/D & 660 \\
\hline
\end{tabular}

Fonte: IISS, 2016.

De acordo com dados disponíveis no próprio site da USPACOM, existem aproximadamente 375.000 militares e civis ordenados para a área de responsabilidade da USPACOM.

Forças da Marinha, Pacífico inclui duas Forças Expedicionárias da Marinha e cerca de 86,000 soldados e 640 aeronaves designadas. As Forças Aéreas do Pacífico dos EUA são compostas por aproximadamente 46,000 aviadores e civis e mais de 420 aeronaves. O Exército do Pacífico dos EUA é composto por aproximadamente 106,000 pessoas de uma corporação e de duas divisões, além de mais de 300 aeronaves e cinco embarcações designadas em todo a área de responsabilidade (AOR) do Japão e da Coréia até o Alasca e o Havaí. Além disso, o comando é composto por mais de 1,200 funcionários de Operações Especiais. O departamento de Defesa conta com 38,000 civis na área de responsabilidade do Comando do Pacífico ${ }^{36}$ (USPACOM, 2017, tradução nossa).

No que diz respeito ao total de gastos militares, o EUA é sem sombra de dúvidas o país que mais gasta com defesa, até porque os comandos e bases instaladas em diversos outros países - mesmo que custeadas em conjunto em alguns momentos - consomem parte do montante de gastos. De acordo com SIPRI de 2016, o EUA gastou US\$ 596 bilhões em 2015 e estima-se a previsão de um orçamento superior a este no ano de 2017.

Como é possível notar, a capacidade militar norte-americana também está alicerçada aos acordos realizados tanto com a Coreia do Sul, ${ }^{37}$ como o Japão. No caso do território japonês, as tropas norte-americanas têm acesso à bases aéreas em Misawa, Yokota e Kadena, além de bases navais em Yokosuka, Atsugi e Sasebo. E talvez a mais importante a base em Okinawa que já levantou diversas manifestações nos últimos anos. No caso da Coreia do Sul, o EUA mantém facilidades em Daegu, Yongsan em Seoul, e Camps 
Red Cloud/Casey e Humphreys. Além de bases aéreas de Osan e Kunsan e navais em Chinhae (Index of us Military Strength 2017).

Os EUA surgem no contex to do Nordeste asiático como um poder contrabalanceador das forças chinesas, ainda mais se olharmos para os gastos de defesa da China em comparação aos países da região, como Coreia do Sul e Japão (Gráfico 1)

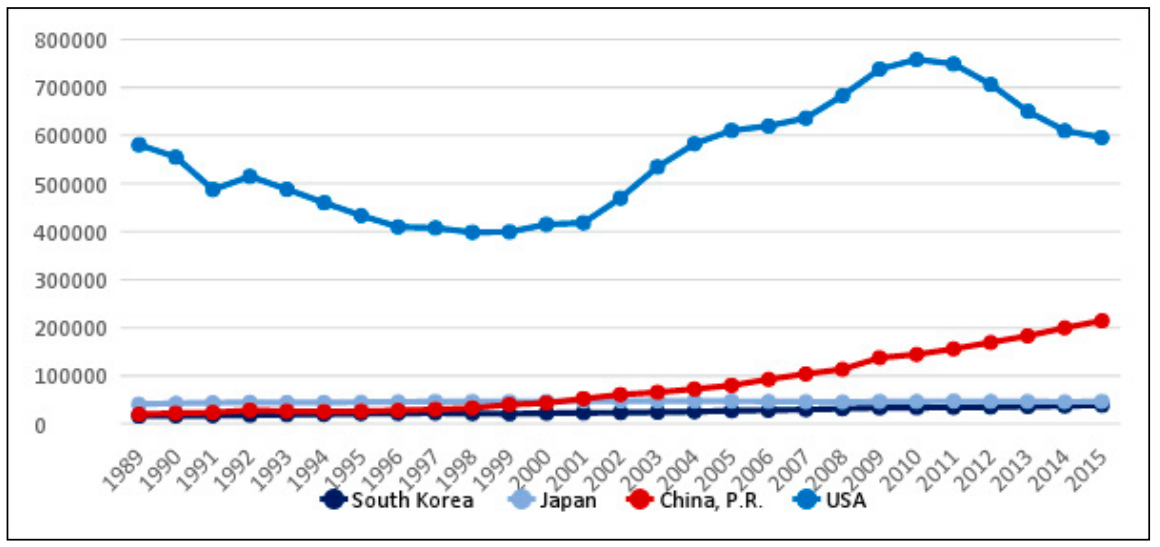

Gráfico 1 - Gastos com Defesa Nordeste Asiático (Países Selecionados)

Fonte: Elaboração própria com base nos dados SIPRI, 2016.

\section{CONCLUSÃO}

O Japão passou por grandes transformações após a Segunda Guerra Mundial, como expomos no decorrer do artigo, sendo a questão militar um dos pontos centrais para se pensar na política externa japonesa. Entretanto, a despeito das cláusulas impossibilitando o poder militar japonês, o Japão é um país extremamente militarizado, sendo um dos países que mais gasta com defesa no mundo (SIPRI, 2016; IISS, 2016).

Ou seja, apesar de constrangimentos impostos pelas próprias amarras e regras constitucionais e até mesmo pelo próprio ideário pacifista que permeou a política japonesa, com o intuito de que o Japão fosse capaz de se reerguer economicamente e se estabilizar em um cenário pacífico e de harmonia. Todavia, como mostram os livros de Defesa do Japão existem justificativas para modificar as cláusulas constitucionais japonesas e parte destes argumentos são respaldados nas ameaças do entorno regional, seja pela ascensão chinesa ou lançamento de mísseis da Coreia do Norte. Outro ponto de justificativa é a necessidade de enviar tropas para auxiliar aliados em outros locais do mundo. 
Tentamos demonstrar de forma breve algumas questões relacionadas aos aspectos de segurança e insegurança no entorno regional japonês, assim como a relevância dos EUA nesta dinâmica, surgindo como um ator central, como aliado estratégico do Japão, com a capilaridade de poder norte-americano. Não se pode desconsiderar também que analisamos o lado japonês, visto que observando os outros atores regionais, as cicatrizes de guerra ainda existem e há uma desconfiança para com o Japão devido às suas conquistas imperialistas no século XIX e XX.

\section{REFERÊNCIAS}

Abe, S. 2012. Asia's Democratic Security Diamond. Project Syndicate. Disponível em: https://www.project-syndicate.org/print/a-strategic-alliance-for-japan-and-india-by-shinzo-abe. Acesso em: 10 maio 2016.

Berger, T. 2014. Abe's Perilous Patriotism. Why Japan's New Nationalism Still Creates Problems for the Region and the U.S.-Japanese Alliance. A Japan Chair Platform Special Edition. Center for Strategic \& International Studies.

Buzan, B. 1983. People, States and Fear: the National Security Problem in International Relations. Hemel Hempstead: Harvest Wheastsheaf.

. 1986. A Framework For Regional Security Analysis. In: Buzan, B., Rizvi, G. South Asian Insecurity and the Great Powers. New York: Palgrave Macmillan.

. 1991a. People, States and Fear: an Agenda for International Security Studies in the Post-Cold War Era. Boulder: Lynne Rienner Publishers.

1991b. New Patterns of Global Security in the Twenty-First Century. International Affairs, 67 (3), 431-451.

Buzan, B.; Hansen, L. 2012. A evolução dos estudos de segurança internacional. Coleção paz, defesa e segurança internacional. São Paulo: Editora Unesp.

Buzan, B.; Waver, O. 2003. Regions and Powers. The structure of international security. Cambridge: Cambridge University Press.

Christensen, T. J. 1999. China, the US-Japan Alliance, and the Security Dilemma in East Asia. International Security, 23 (4) 49-80.

Cooney, K. 2006. Japan's Foreign Policy since 1945. New York: M. E. Sharpe.

Defense of Japan. 2005. Defense of Japan. Disponível em: http://www.mod. go.jp/e/publ/w_paper/2005.html. Acesso em: 10 maio 2016. 
2006. Defense of Japan.

2007. Defense of Japan.

2008. Defense of Japan.

.2009. Defense of Japan.

2010. Defense of Japan.

2011. Defense of Japan.

2012. Defense of Japan.

2013. Defense of Japan.

2014. Defense of Japan.

2015. Defense of Japan.

Embaixada Japão. 2015. Governo Japonês. Disponível em: http://www.br.emb-japan.go.jp/cultura/constituicao.html Acesso em: 10 fev. 2015.

Forsberg, A. 2000. America and the Japanese Miracle. The Cold War Context of Japan's Postwar Economic Revival, 1950-1960. The University of North Carolina Press.

Gao, B. 1997. Economic Ideology and Japanese Industrial Policy: Developmentalism from 1931 to 1965. Cambridge: Cambridge University Press.

Gordon, A. 2003. A Modern History of Japan: From Tokugawa Times to the Present. Oxford: Oxford University Press.

Hamada, K., Mimaki, S. 2011. Chapter 9: The "Yoshida Doctrine" in the post-Cold War world: 'Pre-emptive' minimalist strategy in a multipolar world. In: Hamada, K. et al. Miraculous Growth and Stagnation in Post-War Japan. London: Routledge.

Hashimoto, A. 2016. Nationalism, Pacifism, and Reconciliation: Three Paths Forward for Japan's "History Problem”. The Asia-Pacific Journal. Japan Focus, 14 $(20,4)$.

Herz, J. 1950. Idealist Internationalism and the Security Dilemma. World Politics, $2(2), 157-180$. 
Hiroito. 1945. Imperial Surrender Broadcast. Disponível em: http://www.japanorama.com/surrendr.html. Acesso em: 02 jul. 2014.

IISS. 2016. The Military Balance: the annual assessment of global military capabilities and defense economics.

Index of Military Strength. (2017) Asia. Disponível em: http://index.heritage. $\mathrm{org} / \mathrm{military} / 2017 /$ assessments/operating-environment/asia/. Acesso em: 19 jun. 2017.

Japan Times. 2015. Diet enacts security laws, marking Japan's departure from pacifism. Disponível em: http://www.japantimes.co.jp/news/2015/09/19/national/politics-diplomacy/diet-enacts-security-laws-marking-japans-departure-from-pacifism-2/. Acesso em: 10/05/2016.

Maeda, T. 1995. The hidden Army: the untold history of Japan's Military Forces. Carol Stream: Edition q.

Magalhães, N. S. 2007. Realismo tridimensional e o futuro do Nordeste Asiático. Revista Relações Internacionais, 16, 37-59.

Mainichi. 2016. How much does Japan pay to host U.S. military forces? Disponível em: https://mainichi.jp/english/articles/20160530/p2a/o0m/ona/017000c. Acesso em: 18 jun. 2017

Mastanduno, M. 2003. The U.S.-Japan Alliance and Models of Regional Security Order 21. In: Ikenberry, G. J., Inoguchi, T. (Ed.). Reinventing the Alliance: U.S.-Japan Security Partnership in an Era of Change. New York: Palgrave Macmillan.

Mearsheimer, J. 2001. The Tragedy of Great Power Politics. New York: WW Norton.

Mearsheimer, J. 2004. Why China's Rise Will Not Be Peaceful. Disponível em: http://mearsheimer.uchicago.edu/pdfs/Ao034b.pdf. Acesso em: 15 abr. 2015.

Meissner, W. 2006. China's Search for Cultural and National Identity from the Nineteenth Century to the Present. Chinas's Perspective, 68, 41-54.

Morgenthau, H. J. 2003. A política entre as nações: a luta pela guerra e pela paz. Brasília: Imprensa Oficial do Estado de São Paulo.

OEC. 2016. The Observatory of Economic Complexity. Japan. Disponível em: http://atlas.media.mit.edu/pt/profile/country/jpn/. Acesso em: 01 jun. 2016. 
Oliveira, A. C. G. 2015. A geopolítica da energia e do desenvolvimento no Leste Asiático: as Ilhas Senkaku/Diaoyu e as tensões sino-japonesas. Revista Ponto de Vista, 1 .

Pyle, K. B. 2007. Japan Rising: the resurgence of Japanese power and purpose. New York: Public Affairs.

San Francisco Treaty Peace. 1951. Disponível em https://treaties.un.org/doc/ Publication/UNTS/Volume\%20136/volume-136-I-1832-English.pdf. Acesso em: 17 jul. 2015

Schaller, M. 1987. The American Occupation of Japan: the Origins of the Cold War in Asia. Oxford: Oxford university press.

SIPRI. 2016. Defense Database Expenditure. Disponível em: http://www.sipri. $\mathrm{org} / \mathrm{research} / \mathrm{armaments} / \mathrm{milex} / \mathrm{milex}$ _database/milex_database. Acesso em: 15 maio 2016.

Spykman, N. 1938. Geography and Foreign Policy I. The American Political Science Review, 32 (1).

Tanno, G. 2003. A contribuição da escola de Copenhague aos estudos de segurança internacional. Contexto Internacional, 25 (1) 47-80.

The Constituition of Japan. 1947. The Constituition of Japan. Disponível em: http://afe.easia.columbia.edu/ps/japan/constitution_1947.pdf. Acesso em: 15 jun. 2014 .

Uehara, A. 2003. A política externa do Japão no final do século XX. O que faltou? Fundação Japão. Annablume. Selo Universidade.

USPACOM. 2017. US. Pacific Comand. Headquarters, United States Pacific Command. Disponível em: http://www.pacom.mil/About-USPACOM/. Acesso: 20 de julho de 2017.

Watanabe, P. D. 2011. A política externa do Japão no Pós-Segunda Guerra Mundial e os Estados Unidos da América.

2016. A política de defesa do Japão na primeira década do século XXI. Tese de Doutorado.Universidade de Campinas, São Paulo.

Wolfers, A. 1952. "National Security" as an Ambiguous Symbol. Political Science Quarterly, 67 (4) 481-502. 


\section{NOTAS}

1. As tensões existentes no Mar do Sul da China (MSC) estão escalonando em níveis alarmantes no século XXI. As reivindicações sobre a soberania das ilhas na região envolvem questões históricas e trazem um discurso constante de insegurança no Mar do Sul. As principais disputas são pelo arquipélago de Paracel e pelo arquipélago de Spratlys, além de outras.

2. Dos países que configuram a região, o conflito mais notório no âmbito territorial é a disputa pelas ilhas Senkaku/Diaoyu/Diaoyutai, tendo em vista que tais pequenas ilhotas rochosas são disputadas por três players na região: o Japão, a China e Taiwan. Tal conflito é oriundo de dissuasões históricas e evoca um passado de guerra e humilhação. É o objeto de análise desta pesquisa (Oliveira 2015).

3. Os principais destinos de exportação do Japão são a China (\$131 Bilhões), os Estados Unidos (\$128 Bilhões), a Coreia do Sul (\$52,5 Bilhões). As origens principais de importação do Japão são a China (\$166 Bilhões), o Estados Unidos (\$67,5 Bilhões), a Austrália (\$43,1 Bilhões), a Arábia Saudita (\$42,5 Bilhões) e os Emirados Árabes Unidos (\$37,5 Bilhões) (OEC, 2016).

4. No original: "Because the geographic characteristics of states are relatively unchanging and unchangeable, the geographic demands of those states will remain the same for centuries, and because the world has not yet reached that happy state where the wants of no man conflict with those of another, those demands will cause friction. Thus at the door of geography may be laid the blame for many of the age-long struggles which run persistently through history while governments and dynasties rise and fall”.

5. A hegemon is a state that is so powerful that it dominates all the other states in the system. No other state has the military wherewithal to put up a serious fight against it. In essence, a hegemon is the only great power in the system. A state that is substantially more powerful than the other great powers in the system is not a hegemon, because it faces, by definition, other great powers (Mearsheimer 2001, 83).

6. No original "After pondering deeply the general trends of the world and the actual conditions obtaining in Our Empire today, We have decided to effect a settlement of the present situation by resorting to an extraordinary measure. We have ordered Our Government to communicate to the Governments of the United States, Great Britain, China and the Soviet Union that Our Empire accepts the provisions of their Joint Declaration. [...] We declared war on America and Britain out of Our sincere desire to ensure Japan's self-preservation and the 
stabilization of East Asia $[\ldots]$ the war situation has developed not necessarily to Japan's advantage, while the general trends of the world have all turned against her interest. Moreover, the enemy has begun to employ a new and most cruel bomb, the power of which to do damage is indeed incalculable, taking the toll of many innocent lives. Should We continue to fight, it would not only result in an ultimate collapse and obliteration of the Japanese nation, but also it would lead to the total extinction of human civilization".

7. "A Constituição do Japão declara um sistema de democracia representativa no qual a Dieta é o "órgão mais alto de poder do Estado". Desse modo, a designação do primeiro-ministro, que chefia o poder executivo, é feita após uma resolução da Dieta. O Japão pratica um sistema parlamentarista no qual o primeiro-ministro aponta a maioria dos membros do seu gabinete dentre os membros da Dieta. O gabinete, por sua vez, trabalha juntamente com a Dieta e é responsável por ela. A Dieta está dividida em duas câmaras: a câmara inferior, ou Câmara dos Representantes, e a câmara superior, ou Câmara dos Conselheiros" (Embaixada Japão 2015).

8. Disponível em: http://www.br.emb-japan.go.jp/cultura/constituicao. html.

9. No original "Article 9. Aspiring sincerely to an international peace based on justice and order, the Japanese people forever renounce war as a sovereign right of the nation and the threat or use of force as means of settling international disputes. In order to accomplish the aim of the preceding paragraph, land, sea, and air forces, as well as other war potential, will never be maintained. The right of belligerency of the state will not be recognized".

10. No Artigo 2 do Capítulo 2 do tratado, quando é mencionada a questão do território. O Japão passa a reconhecer a independência coreana, incluindo as ilhas de Quelpart, Port Hamilton and Dagelet. Além disso o Japão renuncia ao território de Formosa (Taiwan) e a Ilha dos Pescadores; e qualquer direito sob o território das Ilhas Curill e parte de Sakhalin; e por último o Japão renuncia qualquer direito ou título das ilhas Spratly e Paracel (San Francisco Treaty 1951).

11. É importante apontar que o Japão custeia cerca de $75 \%$ dos custos das bases norte-americanas em seu território, os tratados de segurança previam que o "Japan must bear the costs relating to hosting U.S. bases while the United States pays for maintaining U.S. military facilities and operational expenditures. In the late 1970s, when Japan was seeing rapid economic growth and consumer price increases while the U.S. economy was in trouble, Japan also agreed to pay part of the labor 
costs for non-military base employees as well as facility maintenance costs. Since fiscal 1987, Japan has been paying the entirety of those labor expenses plus utility costs that are supposed to be covered by the U.S. These payments are covered under something called the "sympathy budget," with which Japan sought to allay criticism that Japan was getting a "free ride" on defense" (Mainichi 2016).

12. Diretrizes estabelecidas em 1950 pelo Primeiro Ministro Yoshida Shigeru.

13. No original "Western nations basically do not fear Japan militarily, but many Asian nations have concerns based on their own historical experience with Japanese militarism. Western nations would prefer that Japan be an active player in the world scene, while many inside Japan and Asia feel that Japan is not ready for this role. With regard to Japan, the world can basically be divided into those who believe that Japan has something to offer the international community and those who do not".

14. O objetivo da RPN era manter ordem interna, não tinha o intuito de substituir as tropas aliadas, mas como os EUA precisavam de apoio nas Guerras das Coreias, o contingente diminuiu e foi necessário criar um novo mecanismo de segurança para afastar ameaças internas e externas do Japão.

15. No original "The Korean War accelerated many trends, yet the outline of American policy toward Japan, China, Korea, and Vietnam for the next twenty years was set even before the fighting began. Perhaps Yoshida Shigeru spoke a truth (if not the truth) when he predicted, in 1950, that, like the changing balance between the American colonies and imperial Britain more than a century before, if Japan temporarily became a "colony of the United States, it [would] also eventually become the stronger."

16. Na Guerra do Golfo, o Japão se recusou a mandar tropas para o exterior, tendo em vista o artigo $9^{\circ}$ da Constituição de 1947 e a cultura pacifista que já permeava o ideário dos cidadãos japoneses. Antes da Guerra do Golfo, os políticos japoneses nunca pensaram na ideia de mandar Forças de Defesa para outros países. Todavia, como o Japão importava grandes quantidades de petróleo do Oriente Médio, as pressões dos EUA ao país participar mais da guerra fez com que o governo japonês aprovasse em 1990 o plano para mandar o "United Nations Peace Cooperation Team” para a Arábia Saudita, mas devido a protestos dentro do Japão a lei foi retirada e só é aceita dois anos depois.

17. Nota-se que nesse período o Japão reestabeleceu as relações diplomáticas tanto com a Coreia do Sul, quanto com a China na década de 1970. 
A Chamada Doutrina Fukuda em 1978 impulsionou as relações diplomáticas do Japão com o sudeste asiático, provendo ajuda e desenvolvimento econômico para a região (Uehara 2003).

18. Na Guerra do Golfo, o Japão ofereceu inicialmente uma ajuda de 400 milhões de dólares aos EUA, todavia foi criticado, questionado e alguns dias depois a quantia subiu para quatro bilhões de dólares. O Japão se recusava a mandar tropas para o exterior, tendo em vista o artigo $9^{\circ}$ da Constituição de 1947 e a cultura pacifista que já permeava o ideário dos cidadãos japoneses. Entretanto, como o Japão comprava grande quantidade de petróleo do Oriente Médio, a posição de afastamento em relação ao conflito, através de um financiamento de tropas, foi vista de maneira negativa no mundo. Nota-se que as pressões continuaram e o Japão doou treze bilhões de dólares para auxiliar na Guerra do Golfo (1990-1991), mas mesmo sendo um dos maiores financiadores, sua imagem foi constantemente questionada (Cooney 2006, 38-43).

19. Governo de Kaifu Bill (1989-1991) do PLD.

20. A lei foi aceita durante o governo do Primeiro Ministro Kiichi Miyazawa (1991-1993) do PLD e previa que o Primeiro Ministro não precisaria passar pela aprovação da Dieta para mandar tropas de Forças de Defesa para atividades como transporte, comunicação, construção, assistência humanitária internacional e funções administrativas. Para enviar as tropas em atividades de monitoramento, supervisão, patrulha e outras, era necessária a aprovação da Dieta Nacional. (Cooney 2006).

21. Mais informações disponíveis em: http://www.mofa.go.jp/policy/un/ pko/pamph96/02_4.html

22. O Japão implantou pelo menos três sistemas de defesa antimísseis Patriot PAC-3 e também possui o sistema de SM-3.

23. Segundo dados da OEC (2016) 22\% dos produtos importados pelo Japão são de origem chinesa, enquanto $18 \%$ dos produtos exportados pelo arquipélago tem como origem destino a China (OEC 2016).

24. No final do século XIX, o sistema tributário chinês é desfeito, sistema que liderava desde a dinastia Ming (1368-1644).

25. Primeira (1894-1895) e a segunda (1937-1945).

26. Nos Livros de Defesa, o terrorismo é um tema constantemente tratados pelos japoneses. É constantemente mencionado a ajuda humanitária japonesa e as guerras no Oriente Médio.

27. No original "On the military front, China has been strengthening its military forces broadly and rapidly by sustaining large increases in its defense budget. (...) As part of such efforts, it is believed that China is enhancing its asymmetric military capabilities to deter military forces 
of other countries from approaching and advancing to China's surrounding region, and to inhibit their military activities (...)”.

28. Assunto tratado em outro artigo publicado na revista NEIC. O debate a respeito do controle das ilhas voltou para as mídias nacionais e internacionais de cada país após um barco pesqueiro chinês colidir com um navio oficial japonês em 2010. Os oficiais japoneses prenderam o capitão do barco pesqueiro e decidiram colocá-lo para julgamento. China acreditava que os dois governos tinham o entendimento que se um navio chinês ficasse em até 12 milhas náuticas das ilhas, os japoneses poderiam expulsá-los, mas não prendê-los (Oliveira 2015).

29. No original "The Chinese and Japanese lived as Asian neighbors for nearly two thousand years. Being geographically so close and yet psychologically quite remote, despite their common cultural roots, the two peoples have developed a sense at once of commonality and disparity, interdependence and autonomy, mutual respect and suspicion, attraction and repulsion, and admiration and condescension toward one another".

30. Os números foram retirados do relatório do IISS de 2016. É necessário ponderar que no caso são valores aproximados. Mais informações sobre poder militar na capacidade tecnológica e de armamentos podem ser encontrados em tal relatório.

31. O Japão fica atrás somente: 1) EUA, 2) China, 3) Arábia Saudita, 4) Rússia, 5) Reino Unido, 6) Índia e 7) França.

32. Diferente da Guerra do Golfo, agora as FAD poderiam ser alocadas em regiões de combate.

33. Além disso, no Livro Branco de Defesa do Japão de 2014 e 2015, por exemplo, são retratadas as questões estratégicas no âmbito da segurança e tratam da relação do Japão com seus vizinhos regionais (Defense of Japan 2014; 2015). Nos livros são tratados os treinamentos militares, capacidades e gastos de defesa. A respeito da China são retratadas as animosidades chinesas com vizinhos em territórios no Sudeste asiático, as ilhas Spratlys e Paracells. Com relação a China, os livros tratam a temática enfatizando questões de insegurança devido aos gastos expressivos e a expansão chinesa para os mares e territórios próximos de delimitações territoriais japonesas.

34. No original "Yet, increasingly, the South China Sea seems set to become a "Lake Beijing," which analysts say will be to China what the Sea of Okhotsk was to Soviet Russia: a sea deep enough for the People's Liberation Army's navy to base their nuclear-powered attack submarines, capable of launching missiles with nuclear warheads. Soon, the PLA Navy's newly built aircraft carrier will be a common sight - more than sufficient to scare China's neighbors". 
35. As Ilhas Senkaku/Diaoyu/Diaoyutai são constituídas por cinco pequenas ilhotas rochosas desabitadas e localizadas na parte leste do Mar da China, distanciando-se de cerca de 120 milhas náuticas a nordeste de Taiwan, 200 milhas náuticas a leste da China e 200 milhas náuticas a sudeste de Okinawa (Japão). A disputa pelas ilhas está envolta em questões nacionalistas, históricas e territoriais. Tanto a China como o Japão e Taiwan, revindicam a posse pelas ilhas (Oliveira 2015).

36. No original "Marine Corps Forces, Pacific includes two Marine Expeditionary Forces and about 86,000 personnel and 640 aircraft assigned. U.S. Pacific Air Forces comprises of approximately 46,000 airmen and civilians and more than 420 aircraft. U.S. Army Pacific has approximately 106,000 personnel from one corps and two divisions, plus over 300 aircraft and five watercraft assigned throughout the AOR from Japan and Korea to Alaska and Hawaii. Of note, component command personnel numbers include more than 1,200 Special Operations personnel. Department of Defense civilian employees in the Pacific Command AOR number about 38,000"

37. A relação entre os dois países envolve um comando integrado que foi estabelecido em 1950, chamado United Nations Command (UNC), e remanesceu no território após um armistício em 1953, ao final da Guerra da Coreia. 


\section{O PODER MILITAR DO SOL NASCENTE: \\ O JAPÃO, A MILITARIZAÇÃO E O ENTORNO REGIONAL}

\section{RESUMO}

Diante das grandes transformações na Ásia, o artigo pretende compreender a política externa japonesa do Pós Segunda Guerra Mundial, através de uma análise voltada para: a) as relações próximas do Japão com os EUA, b) o papel e a constituição das Forças de Defesa, c) o processo de remilitarização ou securitização no século XXI e d) a insegurança no entorno regional japonês.

Palavras-chave: Segurança; Relações Diplomáticas Japonesas; Políticas Externa; Remilitarização.

\section{ABSTRACT}

Facing the great transformations in Asia, this article intends to comprehends the Japanese foreign policy after the Second World War, analyzing: a) Japan-US close, b) the constitution of the Japanese Forces of Self Defense, c) the remilitarization or securitization process in the 21 st century and d) the insecurity in Japan's regional surroundings.

Keywords: Security; Japanese Diplomatic Relations; Foreign Policy; Remilitarization. 